\title{
LA SUBJETIVIDAD HUMANA EN LA ERA DIGITAL "DIME CÓMO LEES Y TE DIRÉ QUIÉN ERES"
}

\author{
Philipp W. Rosemann*
}

RESUMEN: ¿En qué clase de seres humanos nos estamos convirtiendo con la lectura de textos que ya no se imprimen en páginas encuadernadas en libros, sino que se almacenan en la web y que se nos presenta en las pantallas electrónicas? En este artículo se compara la transición de la lectio divina a la lectura escolar en la Edad Media, con la revolución digital del siglo XXI. El propósito no es juzgar, sino desarrollar algunos conceptos y categorías que pueden ayudar a entender cómo la lectura de textos digitales está dando forma a una nueva subjetividad humana.

$$
\text { শ্e }
$$

Human SubJectivity in the Digital ERA:

\section{Tell Me How you ReAd AND I Will Tell you Who ARE}

ABSTRACT: What kind of human beings are we becoming by reading texts that are no longer printed on pages bound into books, but that are stored on the Web and presented to us on electronic screens? This article compares the transition from lectio divina to scholastic reading in the Middle Ages with the digital revolution of the twenty-first century. The goal is not to judge, but to develop some concepts and categories that may help us understand how the reading of digital texts is shaping a new human subjectivity.

PALABRAS CLAVE: revolución digital, subjetividad, psicodinámica de la lectura, lectio divina, escolástica.

KEY WORDS: digital revolution, subjectivity, psychodynamics of reading, lectio divina, scholasticism.

RECEPCIÓN: 28 de septiembre de 2014.

APROBACIÓN: 11 de febrero de 2015.

*Universidad de Dallas. 
CITAM Derechos Reservados.

La reproducción total o parcial de este artículo se podrá hacer si el ITAM otorga la autorización previamente por escrito. 


\section{LA SUBJETIVIDAD \\ HUMANA EN LA \\ ERA DIGITAL. \\ "DIME CÓMO LEES \\ Y TE DIRÉ QUIÉN ERES"*}

\section{El siglo XIII fue un tiempo de grandes} cambios sociales y culturales. Fueron tan maravillosos los logros alcanzados por hombres y mujeres de esa época que James. J. Walsh, popular autor y médico de Fordham, la llamó "el siglo mayor". ${ }^{1}$ Entre los avances a los cuales el doctor Walsh dedicó capítulos francamente entusiastas se pueden contar la fundación de universidades, el auge de la pintura y progresos jurídicos como la Carta Magna; también están los viajes de exploración de Marco Polo y los comienzos del comercio moderno en la Liga Hanseática. Sin embargo, aparejados con estos avances hubo cambios igualmente significativos, si bien más sutiles, de los cuales es posible que Walsh no se haya percatado siquiera, pues únicamente han sido objeto de atención para los estudiosos medievalistas de la segunda mitad del siglo XX. Me refiero al hecho de que las personas cultas (en especial quienes estudiaban y enseñaban en las universidades recientemente erigidas) leían de manera diferente a como lo hicieron sus predecesores.

* Traducción de Mauricio Sanders. Una versión corta de este artículo fue presentada ante los profesores del Departamento Académico de Estudios Generales, del Instituto Tecnológico Autónomo de México (ITAM), el 26 de septiembre del 2014. El autor desea expresar su agradecimiento al Profesor Carlos McCadden, por haberlo invitado a impartir esta plática en el ITAM.

${ }^{1}$ Cfr. James J. Walsh, The Thirteenth, Greatest of Centuries, 1907, Nueva York, Catholic Summer School Press. 
I

Antes del establecimiento de las universidades (aproximadamente en el siglo XII), los monasterios funcionaban como centros de la educación en Europa. En esas circunstancias, lo natural era que la educación estuviera ordenada hacia fines monásticos, de naturaleza eminentemente contemplativa más que práctica o incluso intelectual. Así pues, un monje estudiaba, leía y escribía no para dominar el mundo, sino para conocer y servir a Dios. Uno de los medios primordiales para lograrlo era la recitación de la Palabra de Dios en la comunidad monástica. Al leer juntos y en voz alta textos litúrgicos importantes, como los Salmos, se ayudaba a los monjes no solamente a contemplar la Palabra, sino a asimilarla físicamente, a que se transformaran en la palabra memorizando no solo la forma de las palabras, sino también su sonido y lo que se siente al pronunciarlas. La literatura en torno a las Escrituras resultaba interesante en tanto que pudiera iluminar la Palabra. Ello no supone que las lecturas de los monjes fueran estrechas (eran muy amplias) sino que estaban claramente enfocadas en la organización jerárquica. De hecho, hasta el siglo XII la educación occidental se ciñó en buena medida a las estructuras construidas por San Agustín en su tratado De doctrina christiana. ${ }^{2}$

Cuando la educación se trasladó a las ciudades, se volvió impráctica la profunda asimilación física de textos en comunidad. En las universidades, el edificio del conocimiento adquirió otra estructura, en la cual las llamadas "artes" servían para preparar estudios avanzados en teología, derecho y medicina. Estos estudios resultaban atractivos para estudiantes que estaban interesados no meramente en la búsqueda del conocimiento, sino en hacer carrera: las leyes, la medicina e incluso la teología servían como preparación para lucrativos empleos con influencia en los crecientes cuerpos que administraban ciudades, Estados e Iglesia. Para no perder todo detalle en este recuento asaz amplio, es

${ }^{2}$ Para un relato lleno de vida de la lectura monástica, véase Ivan Illich, In the Vineyard of the Text: A Commentary to Hugh's "Didascalicon", 1993, Chicago y Londres, University of Chicago Press, pp. 1-4. 
importante mencionar que no estamos tratando con un rompimiento radical, sino con un significativo cambio en el énfasis: así como las escuelas monásticas servían para el propósito de ascender socialmente, así un alumno o un profesor universitario no necesariamente era un oportunista escalador; en numerosos casos, las metas de los que buscaban educarse y de quienes les proporcionaban educación eran una mezcla de motivos e intereses.

No obstante, las universidades proporcionaban un marco institucional en el cual el conocimiento ya no estaba explícitamente orientado hacia la contemplación. Asimismo, los maestros que enseñaban en estas universidades eran designados y contratados para enseñar con efectividad, esto es, de manera tal que surtieran "efectos" y produjeran resultados en forma de grados. Esto requería exámenes y pruebas, que eran regulados por diversas facultades que representaban disciplinas con límites precisos. En el siglo XIII se comenzó a distinguir entre filosofía y teología de una manera que resultaría anacrónica si se aplicara a San Agustín o a Erígena.

Pero hablábamos de la lectura. Conforme las disciplinas adquirieron una estructura académica delimitada y los maestros comenzaron a considerarse servidores de las disciplinas, así como sus discípulos, alcanzar cierta eficiencia se convirtió en una preocupación. Podemos encontrar este énfasis sobre la necesidad de concentrarse en lo útil y evitar la pérdida de tiempo en el célebre prólogo a la Summa Theologica de Santo Tomás de Aquino. Ahí, el Doctor Angélico recomienda la obra por sus virtudes pedagógicas.

Así como el doctor en la verdad católica debiera enseñar no solo a los doctos sino también instruir a los que apenas comienzan (de acuerdo con el Apóstol: "Puesto que sois niños en Cristo, les doy leche para alimentarlos y no carne" [1 Cor 3, 1-2]), en este libros nos proponemos tratar con todo aquello que toca a la religión cristiana, en tanto pueda tender a la instrucción de los catecúmenos. Hemos considerado que los estudiosos de esta doctrina suelen verse obstaculizados por aquello que otros escribieron, en parte debido a la multiplicación de cuestiones, argumentos y artículos inútiles; en parte también porque las cosas que necesitan saber no se las enseñan de acuerdo con el orden de la disciplina, sino de acuerdo 
con lo requerido por el plan de su obra o con la ocasión ofrecida para disputar; en parte asimismo porque la reiteración frecuente generaba confusión y enfado en la mente de los lectores. Pretendiendo evitar estos y otros defectos, con la gracia de Dios intentaremos plasmar todo aquello que contiene la doctrina sagrada con toda la brevedad y claridad que permita la doctrina misma. ${ }^{3}$

Estas palabras pudieran parecernos ligeramente cómicas, pues abren una obra que ocupa numerosos volúmenes en las ediciones modernas. Aunque el concepto medieval de lo breve y de lo conveniente por un principiante puede haber sido diferente del nuestro, lo relevante es que el Aquinate subraya la necesidad de enseñar teología con eficiencia.

Un siglo después de la Summa, el Libro de las sentencias, de Pedro Lombardo, habría de convertirse en el libro de texto canónico para enseñar teología en las universidades. Lombardo hizo declaraciones semejantes en el preámbulo de su obra, encomiando su brevedad y facilidad de uso. Concluye su prefación llamando la atención del lector sobre el hecho de que su obra inicia con un índice de materias. ${ }^{4}$

Dicho índice resultó ser una innovación que intervino en la transición de la lectio divina, o lectura divina, de los monasterios hacia un enfoque más escolástico del uso y consulta de textos. En las obras escolásticas cobró importancia asegurar que pasajes selectos pudieran ser localizados rápida y fácilmente, de modo que un profesor o un alumno pudieran citarlos en sus disputas. Más aún, conforme los maestros componían gruesos manuales de teología como el Libro de las sentencias o la Summa tenían que recuperar materiales tomados de la Escritura y otros textos de autoridades, con el fin de incorporarlos a un nuevo contexto. Fue entonces que la lectura escolástica dejó de recalcar la asimilación profunda de la Palabra, a favor de la localización de textos que pudieran ser trabajados en formas creativas y novedosas. El método escolástico requería índices de materias, pero también índices onomásticos, glosarios y otras herramientas para el estudio, las cuales proli-

${ }^{3}$ Tomás de Aquino, Summa theologiae, prólogo, traducción de los Fathers of the English Dominican Providence, ligeramente modificada.

${ }^{4}$ Cfr. Pedro Lombardo, Sententiae in IV libris distinctae, 3a ed. Grottaferrata, Editiones Collegii S. Bonaventurae Ad Claras Aquinas, 1971-1981, prólogo, vol. 1, pp. 3-4. 
feraron en el periodo escolástico. La consulta expedita y eficiente por parte del profesor o el alumno en forma individual vino a reemplazar la recitación comunitaria que caracterizó a la lectura monacal. ${ }^{5}$

En ese proceso, la página quedó en silencio: ya no había tiempo para leer en voz alta ni había nadie para escuchar. Esto implica que la existencia espacial de las palabras adquirió una significancia de la que carecía previamente, cuando la Palabra era principalmente para ser escuchada, aunque estuviese preservada en el espacio sobre una página. Alguien pudiera argumentar que, al convertirse la lectura escolástica en la forma paradigmática para abordar textos en una universidad medieval, la cultura occidental se hizo más optocéntrica. En confirmación de esta idea resulta interesante notar que los autores escolásticos utilizaron diagramas de forma abundante, pues les ayudaban a entender conexiones complejas entre conceptos, e incluso entre las vastas estructuras conceptuales que son los sistemas teológicos completos.

¿Cuál es la diferencia entre escuchar palabras y leer textos? A mí me parece que lo fundamentalmente diferente estriba en la evanescencia de la palabra hablada, que obliga a quien escucha a poner atención: la palabra hablada sujeta a quien la escucha. En cambio, congeladas sobre la página, las palabras son sujetadas por la mirada del lector, quien puede volver a ellas a voluntad y así manipularlas al moverlas a su antojo, reuniéndolas en diccionarios e insertándolas en contextos diferentes. La palabra en el espacio, en oposición a la palabra en el tiempo, crea un sentido de subjetividad que casi es moderno, en especial si se considera que la Escritura misma, la Palabra de Dios, quedó sujeta al tratamiento escolástico. ${ }^{6}$

${ }^{5}$ Por el lugar que las herramientas de estudio jugaron en la educación escolar, véase Mary A. Rouse y Richard H. Rouse, Authentic Witnesses: Approaches to Medieval Texts and Manuscripts, 1991, Notre Dame, University of Notre Dame Press, y Olga Weijers, Le maniement du savoir. Pratiques intellectuelles à l'époque des premières universités, XIIle-XIVe siècles, 1996, Turnhout, Brepols.

${ }^{6} \mathrm{El}$ estudio pionero de los efectos de la espacialización sobre el idioma es de Walter J. Ong, S.J., Ramus, Method, and the Decay of Dialogue: From the Art of Discourse to the Art of Reason, 1958, Cambridge, Mass., Harvard University Press; nueva edición, 2004, Chicago y Londres, University of Chicago Press. 
II

Un monje recita la Palabra en comunidad, la contempla y asimila o, mejor dicho, se asimila a ella. Por otro lado, el escolástico consulta textos con los que trabaja, colocándolos a su placer en otros contextos, en estructuras que él mismo ha ideado, tales como grandes síntesis teológicas. Uno podría decir: "Dime cómo lees y te diré quién eres". Dicho esto, ¿cómo leemos en la era digital?

No se puede responder a esta pregunta con facilidad, pues carecemos de la distancia histórica que nos proporcione los proverbiales "beneficios de la retrospección", que implican la capacidad para considerar un fenómeno tomando en cuenta los beneficios que produjo. Todavía desconocemos en su cabal complejidad todos los efectos que engendrará la era digital.

No obstante, una cosa es cierta: los cambios en la lectura que han sido generados por la era digital no pueden ser comparados directamente con la transición entre la lectura monástica y la medieval. Tanto monjes como maestros escolásticos encontraban las palabras que leían sobre páginas manuscritas (si bien es cierto que, conforme la cultura escolástica fue produciendo los formatos apropiados para sus técnicas de lectura, la página de un comentario del Libro de las sentencias del siglo XIII tenía un aspecto muy diferente al de un salterio del siglo XII). En cambio, la página digital está dejando atrás a la página impresa, y ambas son diferentes por el material de soporte: papel y una pantalla electrónica).

Al comparar la página digital con la impresa, tomando como referencia al manuscrito, nos encontramos con que el texto digital, con toda su posmodernidad, parece compartir características de la textualidad premoderna. Por ejemplo, la imprenta fija los textos sobre la página: una vez que el autor aprueba las revisiones, el texto se forma en plomo para ser difundido en grandes cantidades de copias idénticas. En consecuencia, los textos modernos no necesitan complejas ediciones críticas, como sí sucede con aquellas obras que circularon en forma manuscrita: puesto que ningún manuscrito es idéntico a otro, debido a distracciones 
del copista pero también a omisiones y adiciones deliberadas realizadas por olas sucesivas de escribanos y lectores, a menudo se hace muy difícil, a veces hasta imposible, reconstruir el "original" que, se supone, refleja las intenciones y el pensamiento del autor. Por decirlo de alguna manera, durante largo tiempo el ideal de la edición crítica fue volver al texto arquetípico recorriendo las numerosas ramificaciones que lo transmitieron; esto fue así hasta que los medievalistas se percataron de que estaban imponiendo un paradigma moderno sobre el concepto medieval de autor. ${ }^{7} \mathrm{El}$ autor medieval no estaba tan preocupado como nosotros por cuestiones de originalidad y propiedad intelectual; con frecuencia copiaba pasajes ajenos sin dar crédito alguno, pues esperaba que sus escritos fueran tratados de la misma manera. A menudo los autores medievales refundían sus obras sobre versiones más tempranas ya en circulación, a veces en colaboración con un grupo de discípulos. ${ }^{8}$ Es más, de manera anónima fueron publicados textos muy importantes como la Glosa ordinaria, compilación de comentarios generalmente aceptados a la Biblia, que elucidaban el texto de la Escritura por medio de pasajes apropiados tomados de los doctores de la Iglesia, que se añadían entre líneas o a los márgenes. ${ }^{9}$ De esta manera, la autoría medieval y las prácticas de lectura de la época se parecen al manejo dinámico de textos que se ve favorecido por la publicación en formato digital. Los textos diseminados en las páginas de internet están tanto o más sujetos al cambio que los manuscritos; en numerosos casos, se invita a los lectores a escribir como si fueran autores, y muchas veces escriben bajo seudónimo con su "nombre de pantalla". Por ejemplo, nadie es "autor" de una entrada de la Wikipedia; tampoco hay un texto original que pudiera tener mayor significación que sus redacciones posteriores.

${ }^{7}$ David C. Greetham es uno de los más destacados estudiosos en haber llamado la atención sobre los problemas metodológicos que están involucrados en las técnicas editoriales tradicionales; véase, por ejemplo, su Textual Scholarship: An Introduction, 1992, Nueva York, Garland.

${ }^{8}$ Para una primera orientación, se puede consultar Auctor \& auctoritas. Invention et conformisme dans l'écriture médiévale, 2001, ed. Michel Zimmermann, París, École des Chartes.

${ }^{9}$ Cfr. Lesley Smith, The "Glossa Ordinaria": The Making of a Medieval Bible Commentary, 2009, Leiden y Boston, Brill. 
El hecho de que las páginas presentadas digitalmente puedan ser enrolladas y desenrolladas apunta todavía más atrás en la historia del libro, más allá de la Edad Media hasta llegar al códice y al rollo de la Antigüedad. ${ }^{10}$ Sin embargo, resulta interesante notar que actualmente los aparatos de lectura más avanzados, como el Kindle, imitan a los códices. Sin duda, esto no es sino una concesión para lectores que apenas emergen de la edad de Gutenberg y se sienten más cómodos dando vuelta a una página que desenrollándola. ¿Qué diferencia hay para un lector entre voltear la página y desenrollarla? Una de las ventajas del códice sobre el rollo está en que es más fácil de consultar; mientras que el rollo o papiro en esencia consiste de una sola pieza, el códice parte el texto en unidades menores que, cosidas en cuadernos, permiten recuperar con rapidez relativa pasajes del texto.

A pesar de la similitud que salta a primera vista entre los rollos antiguos y las páginas web enrollables, la facilidad para manipular textos digitales los separa de todos su predecesores, trátese de rollo, códices manuscritos o páginas impresas. Muchos de los instrumentos de consulta que nos son familiares gracias a los libros modernos (instrumentos que facilitan el acceso y recuperación de porciones individuales de vastos textos completos) se originaron en la Edad Media. Ya he señalado cuán orgulloso se sentía Pedro Lombardo del índice de materias contenido en su libro de texto de teología. El índice del Libro de las sentencias funcionaba particularmente bien al usarse junto con los encabezados de capítulo impresos en tinta roja que aparecen a lo largo de la obra. También hay frases en rojo, llamadas "rúbricas", que servían para destacar subdivisiones en los capítulos individuales o fuentes importantes citadas para sostener argumentos e incluso dificultades conceptuales. Los lectores posteriores del Libro de las sentencias a menudo dotaron sus ejemplares de índices detallados ordenados alfabéticamente. Así fue que el moderno libro impreso quedó cargado de divisiones del texto en varios niveles, índices de materias y onomásticos, como lo

${ }^{10}$ Sobre la transición del rollo al códice, véase el studio clásico de Colin H. Roberts y T. C. Skeat, The Birth of the Codex, 1987, Londres, Oxford University Press for the British Academy. 
epitomizan los vastos instrumentos de estudio representados por diccionarios y concordancias.

Lo que resulta ser completamente nuevo en la era digital es la capacidad para vincular un número prácticamente ilimitado de textos en gigantescas bases de datos que arrojan resultados inmediatos al realizar una búsqueda. Además de las bases de datos creadas especialmente para ciertas áreas temáticas, internet es la mayor base de datos de todas. Compárese al monje medieval que practicaba la lectio divina con un usuario de internet que realiza búsquedas para acceder a cierta información: el primero se sujeta a la Palabra con el fin de conformarse a ella; el segundo identifica fragmentos de texto que le resultan útiles o interesantes, de acuerdo con criterios particulares que el lector mismo define. Al romper el texto de manera semejante, este pierde su congruencia y autonomía internas y queda sujeto a ser dominado y manipulado.

Por consecuencia, no resulta extraño si los textos digitales favorecen una forma superficial de lectura que selecciona fragmentos de información más que sumergirse en la lógica interna de un argumento o una narración. ${ }^{11} \mathrm{Si}$ hay alguna subjetividad que pueda corresponder a esta forma de entrar en los textos, sería una subjetividad kantiana: así como el sujeto kantiano es capaz de experimentar la realidad únicamente dentro de un marco cuyos parámetros quedan fijados por su propia mente, así el lector posmoderno posiciona los textos digitales dentro de campos de investigación definidos por sus propósitos personales.

Si a partir de lo anterior parece que la página digital nos lleva más allá de la modernidad hasta prácticas posmodernas de lectura, también hay aspectos de los textos electrónicos que no encajan en este análisis. Ya hemos visto que desenrollar un texto es una tecnología tan antigua como pasar una página. De manera semejante, mientras que la moderna producción de textos y las prácticas de lectura que le son inherentes privilegian el encuentro silencioso con palabras que están disponibles en múltiples copias para los lectores individuales, hay textos

${ }^{11}$ Sobre la lectura superficial, véase Nicholas Carr, The Shallows: What the Internet Is Doing to Our Brains, 2010, Nueva York y Londres, W. W. Norton. 
digitales que otra vez nos dirigen la voz; por ejemplo, los populares audiolibros, que posibilitan la escucha de un texto sin página de por medio, sea impresa o digital. Esto va a contracorriente de la especialización de la palabra que diagnosticamos con relación a la lectura escolástica.

A menudo se repite que una de las diferencias principales entre la página digital y sus antecesoras, manuscritas o impresas, es la inmaterialidad relativa. Lo cierto es que el texto digital requiere un soporte material (como una pantalla y demás equipo para almacenar el texto, procesarlo y visualizarlo), si bien ante el lector las palabras carecen de la misma tangibilidad que en pergamino o papel. Con la excepción de los audiolibros ya mencionados, el texto digital se dirige a uno solo de los cinco sentidos, la vista; no se le puede tocar ni oler como a las hojas de un libro. El texto no arraiga sobre la pantalla, por decirlo de alguna manera, porque no queda fijo de modo permanente, como quedan fijas las palabras en papel o pergamino. Puesto que un texto digital no amarillea ni se torna quebradizo, es un texto que caduca sin envejecer. En consecuencia, el pensador estadunidense Michael Him pudo concluir que la información digital "flota a través de la mente platónica sin aferrarse a la experiencia corporal". ${ }^{12}$

Sin embargo, la inmaterialidad relativa del texto digital tal como aparece ante el lector depende de una enorme red de infraestructura, plantas generadoras de electricidad, servidores, distribuidores y cables. ${ }^{13}$ La diferencia estriba en que el lector puede palpar la materialidad de un libro, mientras que las instalaciones que subyacen a la cultura digital pasan casi desapercibidas, al menos para los ojos de la persona común. De hecho, en esto consiste una de las características de la tecnología avanzada: aliena al usuario que la utiliza sin saber cómo funciona. Ciertamente las habilidades de un maestro escribano eran tan raras y apreciadas como los conocimientos de un ingeniero experto en computadoras o en programación; la diferencia radica en que cualquiera podía aprender nociones de la técnica del escriba, mientras que la

${ }^{12}$ Michael Heim, The Metaphysics of Virtual Reality, 1993, Nueva York, Oxford University Press, p. 101.

${ }^{13}$ Andrew Blum ha dedicado un popular best-seller a este tema: Tubes: A Journey to the Center of the Internet, 2012, Nueva York, Ecco. 
vasta mayoría de quienes trabajan con textos digitales no tienen el adiestramiento avanzado que se necesita para comprender el funcionamiento de los aparatos que usan.

\section{III}

Puede ser que la alienación apenas mencionada se deba a los procesos tecnológicos que permean al mundo digital en que vivimos. No obstante, hay una dimensión adicional que se debe considerar. Recientemente, Richard Keamey acuñó el término "excarnación” para referirse a la condición humana en una sociedad cada vez más "descarnada" en la cual la acción humana pasa por mediadores inmateriales y la interacción conduce a la alienación del cuerpo. ${ }^{14}$ Kearney pone al amor y a la sexualidad como ejemplo, aunque, como ya hemos visto, la "excarnación" gradual también caracteriza a la historia de las técnicas de lectura, historia que por lo pronto culmina en el texto digital. Somos lectores mucho menos encarnados que los monjes que practicaban la lectio divina, quienes le daban vida a la Palabra al encarnarla en sus celebraciones litúrgicas. En comparación, aunque menos encarnados, también somos lectores mucho más poderosos, pues tenemos la herencia escrita del mundo al alcance de la mano (o por lo menos la era digital se propone que lo tengamos). Al alcance de la mano: ya no tenemos que hacer el viaje a la biblioteca, tomar un grueso volumen del estante, buscar palabras impresas con tinta sobre la página y acaso leerlas en voz alta. En vez de eso, utilizamos un motor de búsqueda, que devuelve pasajes que luego copiamos (veloz, silenciosa y fácilmente) en los documentos que estamos creando. Nunca nos apropiamos de los textos: es más, si somos académicos, las notas al pie de página están ahí para indicar que son "propiedad" ajena. ${ }^{15}$

Siempre parece que los instrumentos más o menos complicados que sirven para mediar la acción humana producen una dialéctica entre

${ }^{14}$ Richard Kearney, "Losing Our Touch", The New York Times, vol. CLXIII, no. 56, 610, 31 de agosto 2014, Sunday Review, p. 4.

${ }^{15}$ Sobre la historia de las notas al pie de página, véase Anthony Grafton, The Footnote: A Curious History, 1999, Cambridge, Mass., Harvard University Press. 
alienación y dominio. Montar a caballo es mucho menos fatigoso y más rápido que ir a pie. Durante mucho tiempo el caballo sirvió al hombre como una extensión de sus piernas, y los mediadores de la relación entre ambos cuerpos eran la montura y el fuete. El carro tirado por caballos trajo mayores ventajas, pues le dio al hombre la oportunidad de viajar en un ambiente artificial mejorado, con sillones tapizados y alguna forma de resguardo contra los elementos. Entonces surgió la idea de reemplazar los caballos con "caballos de fuerza" por medios mecánicos, y llegamos al automóvil (que, por cierto, también tiene pies y cara con ojos y boca). ${ }^{16}$ Obviamente, el automóvil ha extendido nuestro rango de movimientos, así como nuestra capacidad para dominar el ambiente, esto es, para tenerlo sujeto en vez de quedar sujetos a sus variaciones. Al mismo tiempo, es un experto quien da mantenimiento a los automóviles; más aún, al olvidar que nuestros pies y piernas son medios naturales de transporte, se ha producido una alienación con respecto a nuestros cuerpos, que cobra forma de obesidad y otras enfermedades relacionadas (si bien en ellas también influyen otros factores).

Así como los instrumentos físicos son extensión de los órganos humanos, la escritura es la extensión o exteriorización de la memoria. ${ }^{17}$ Muchos textos fundamentales de diversas culturas tuvieron una existencia oral durante siglos enteros, antes de ser consignados a la escritura (si es que lo fueron). Como ejemplo se puede mencionar la épica homérica y las Escrituras judías y cristianas. Incluso en mayor grado que la lectio divina medieval (que después de todo se basaba en textos escritos) los textos encarnan en las culturas orales. Más que llevar una existencia estática sobre un trozo de pergamino, una hoja de papel o una tarjeta de memoria, los textos de las sociedades preliterarias existen

${ }^{16}$ En este punto, es interesante recordar la tesis de Ernst Kapp respecto a la "organicidad" de herramientas, es decir, el hecho de que se modelan con base en órganos humanos. Kapp produjo la primera filosofía de la tecnología en su libro, Grundlinien einer Philosophie der Technik. Zur Entstehungsgeschichte der Cultur aus neuen Gesichtspunkten, 1877, Braunschweig, Westermann.

${ }^{17}$ Hablar de los medios de comunicación como "extensiones" del hombre trae a la mente el título del influyente libro de Marshall McLuhan, Understanding Media: The Extensions of Man, 1964, Nueva York, Londres y Toronto, McGraw-Hill. Tenga en cuenta, sin embargo, que la idea de herramientas como extensiones de órganos humanos ya fue articulada por Ernst Kapp en su Grundlinien einer Philosophie der Technik. 
en forma de acción cada vez que se les recita. Las palabras son "actividades, hechos", para decirlo como Walter Ong. ${ }^{18}$ Desempeñan un papel fundamental en las comunidades donde se les declama o canta, y continuamente deben ser adaptados a nuevas situaciones. En este contexto, la tradición no significa un inventario inmutable de principios, sino una transmisión incesante de historias que iluminan la condición humana. El pensamiento no es objetivo sino situacional. Más aún, puesto que las culturas orales deben dedicar considerables esfuerzos mentales a preservar sus tradiciones, su orientación fundamental es literalmente conservadora.

Al liberar la mente de la tarea de memorizar activamente, como sucede en las culturas alfabetizadas, surgen fuerzas innovadoras previamente desconocidas. Imaginemos ahora una situación en la que, como en la era digital, la memoria humana se exterioriza casi por completo; en la que, por ejemplo, todos los eventos memorables de la vida de una persona residen como imágenes digitalizadas dentro de un disco duro o en "la nube", por no mencionar archivos digitales de las comunicaciones de ese individuo con otros ni el conjunto de sus librerías. Es más, imaginemos que la totalidad de la herencia cultural de la raza humana está almacenada digitalmente, al alcance de un clic del ratón. En tales circunstancias, la mente quedaría sin ninguna traba para dedicarse a resolver problemas por medio del pensamiento analítico.

Así pues, diversos modos de exteriorizar la memoria dan lugar a distintas clases de "psicodinámica", para utilizar el término que Walter Ong aplica al comparar las culturas orales con las escritas. Cabría entonces preguntarse si la memoria existe como una simple capacidad "en" la mente, esto es, si existe sin ser ejercitada o, en otras palabras, exteriorizada. Claramente San Agustín era del parecer de que la memoria se forma en la "confesión", pues en el Libro XI pone como ejemplo de la relación entre memoria y tiempo la recitación de un salmo. ${ }^{19} \mathrm{Un}$ filósofo más próximo a nuestros tiempos, Martin Heidegger, diría que la persona humana es un ser que siempre se encuentra en-el-mundo; en

${ }^{18}$ Walter J. Ong, S.J., Orality and Literacy: The Technologizing of the Word, 2008, Londres y Nueva York, Routledge, p. 31.

${ }^{19}$ Véase Agustín, Confessions, XI.28.38. 
otras palabras, un ser inconcebible sin "lo exterior". En nuestro contexto resulta interesante notar que, según lo consigna Ser y tiempo, este seren-el-tiempo implica de manera fundamental instrumentos, herramientas o Zeuge. El mundo como un todo adquiere sentido únicamente a través de la red de significancias que los instrumentos establecen al apuntar unos a otros: el martillo al clavo, el clavo al cuadro, el cuadro a la pared, etcétera.

Habría que preguntarse ahora qué sucedería si la profundidad de la reflexión, de la interioridad, del ser humano estuviera relacionada con su expansión por el mundo, con su exterioridad. Tal es la tesis que Ernst Kapp propone en su obra pionera Grundlinien einer Philosophie der Technik:

Puesto que el ser está encarnado y solamente vive en un cuerpo, este mundo externo de productividad mecánica que tiene su punto de partida en el ser humano puede por tanto ser entendido como una verdadera continuación del organismo, como una proyección hacia fuera del mundo interior de las representaciones. Tal concepto del reino formado por el mundo externo que contiene la totalidad de los medios culturales es la actualización de la naturaleza humana que se expresa a sí misma y, por medio de la acción de reflejar imágenes desde el exterior hacia el interior, se transforma en auto-conocimiento. Esto sucede por medio del hecho de que, al utilizar y considerar comparativamente el producto de sus manos, las leyes y procesos de la vida inconsciente del hombre salen a la conciencia, dando una visión genuina del ser. ${ }^{20}$

Si los instrumentos que utiliza el ser humano para conformar su ambiente son proyecciones del cuerpo y la mente humanos en el

${ }^{20}$ Kapp, Grundlinien einer Philosophie der Technik, p. 26: "Da aber das Selbst, wie oben gezeigt worden, nur in einem Leibe 'leibt und lebt', so kann diese vom Menschen ausgehende äussere Welt mechanischer Werkthätigkeit auch nur als reale Fortsetzung des Organismus und als Hinausverlegung der inneren Vorstellungswelt begriffen werden. Eine derartige Aufnahme dieses die Gesammtheit der Culturmittel umfassenden Gebietes der Aussenwelt ist ein thatsächliches Selbstbekenntniss der Menschennatur und wird durch den Act der Zurücknahme des Abbildes aus dem Aeusseren in das Innere zur-Selbsterkenntniss. Es geschieht dies dadurch, dass dem Menschen beim Gebrauch und bei vergleichender Betrachtung der Werke seiner Hand durch eine wahrhafte Selbstschau die Vorgänge und Gesetze seines unbewussten Lebens zum Bewusstsein kommen." 
mundo que les rodea, entonces el hombre a final de cuentas se encuentra consigo mismo en sus artefactos; y la consideración de este ser objetivizado a su vez conduce a un conocimiento interior más profundo. Podríamos ilustrar esta tesis mediante la historia de la lectura que hemos estado exponiendo, pues en la antigua Grecia el descubrimiento del alma individual que constituye a cada ser humano coincidió con la transición desde el estado mental propio de la oralidad homérica hacia un mundo platónico escrito. La cultura oral no permitió el surgimiento de agentes autónomos a partir de narraciones recitadas en comunidad, que absorbían al oyente dentro de su ritmo y su flujo, realzando la continuidad entre pasado y presente. La introspección exigía la posibilidad de discriminan entre el relato y las circunstancias de aquel quien lo proporcionaba o lo examinaba; en otras palabras, requería la existencia objetiva de un texto escrito. ${ }^{21}$ Más adelante en la historia de Occidente, la diseminación en masa de libros por medio de la imprenta creó la posibilidad de que los individuos ponderaran acerca de textos escritos en ambientes privados, lo cual abrió el camino para una mayor profundización de la autoconciencia, así como el surgimiento del concepto de la esfera de lo privado. ${ }^{22}$ Ambos casos apuntan hacia las relaciones dialécticas entre autoexpresión y autoconocimiento: conforme el ser humano se adentra más en el mundo por medio de mayores poderes para exteriorizar la memoria, su autoconciencia, esto es, la anchura y hondura de su vida interior, se incrementan proporcionalmente.

\section{IV}

Con anterioridad diagnosticamos dos formas de alienación probablemente causadas por la era digital: una, la alienación que resulta de la incapacidad para comprender la complejidad de los procesos técnicos involucrados en la mediación digital del mundo; otra, la alienación del cuerpo en tanto que el mundo digital es descarnado, lo cual conduce

${ }^{21}$ Estoy parafraseando el argumento que Eric Havelock desarrolló en su Preface to Plato, 1963, Cambridge, Mass., The Belknap Press, esp. cap. 11.

${ }^{22}$ Véase Ong, Orality and Literacy, op. cit., p. 128. 
al ser humano a una existencia "excarnada". No obstante, también hemos visto, siguiendo la tesis de Ernst Krupp, que exteriorización no necesariamente implica alienación; por el contrario, la proyección progresiva de los órganos humanos (mente y memoria inclusive) en el mundo puede conducir a la humanización del ambiente, lo cual a su vez permite una mayor profundización en el ser. Sin embargo, a esto debemos añadir: permite una mayor profundización siempre y cuando ocurra (en palabras de Krupp) el acto de "devolver la imagen" del ser que el hombre proyecta al mundo externo "desde afuera hacia adentro". De otra manera el ser no puede reflejarse sobre sí mismo por medio del mundo que encuentra, y termina por disiparse en el mundo.

El riesgo de tal disipación se agudiza cuando el ser humano ya no puede reconocerse en su ambiente: así como el martillo funciona como una extensión y una amplificación de los poderes de la mano del hombre, la computadora constituye una especie de extensión del cerebro, sin que podamos precisar a qué grado es así. Mientras que el diseño y funcionamiento de un martillo resultan obvios, los de una computadora únicamente lo son para los expertos. Más aún (de manera paradójica), el ser "se pierde" cuando ya no puede reconocer la "otredad" de su ambiente, un "objeto" que se opone al ser y por tanto ofrece resisten24 cia a la exterioridad humana. Lo que Martin Heidegger describió como "inobjetividad" (Gegenstandslosigkeit), resultado de "encuadrar" la naturaleza como un mero recurso, implica una amenaza, a saber, que si toda la realidad se disuelve en forma de una "reserva disponible", entonces se corre el peligro de que hasta los seres humanos se conviertan en meros "recursos humanos" para la expansión incesante de los procesos tecnológicos. ${ }^{23}$ Georg Simmel identificó una amenaza similar en la economía monetizada avanzada que rige sobre el mundo contemporáneo: cuando el dinero se convierte en el objetivo primordial de la actividad económica, las personas que participan en dicha actividad pierden la oportunidad de formarse por medio del trabajo. Por ejemplo, un zapatero adquiere una personalidad particular al interactuar con los materiales necesarios para producir zapatos; lo mismo

${ }^{23}$ Véase Martin Heidegger, “The Question Concerning Technology,” trad. William Lovitt, en David Farrell Krell (ed.), Basic Writings, 1993, San Francisco, HarperCollins, pp. 307-41. 
sucede con el terrateniente responsable de administrar sus propiedades o con el dueño de una fábrica cuya personalidad se moldea por las exigencias que le impone una cierta industria. Por el contrario, quien posee dinero experimenta una completa libertad con respecto a sus posesiones: su haber (Haben) ya no conforma su ser (Sein), y esto por causa de la naturaleza del dinero, que carece de toda sustancia y es función de intercambio pura. ${ }^{24}$

Los análisis de Heidegger y Simmel apuntan al peligro inherente en la exteriorización digital de la memoria, y también advierten contra la naturaleza cada vez más "excarnada" de nuestras interacciones con el ambiente: no podemos experimentar la "otredad" de aquello que manejamos digitalmente. Ya hemos considerado cuán grande es la tentación de tratar textos almacenados en bases de datos como si fueran meros insumos para nuestros proyectos intelectuales; desgajadas de su contexto, consultadas en la superficie, las palabras pierden su poder original, que incluye el poder para transformar una vida. De nuevo, compárese la recitación de un poema homérico en la Grecia prealfabetizada o la lectura litúrgica de un pasaje de las Escrituras con la forma que un académico o un universitario moderno encuentra textos semejantes usando un motor de búsqueda, para luego copiarlos y pegarlos sobre una pantalla. Más aún, puesto que por medios digitales se incrementa el poder de los instrumentos que utilizamos para lidiar con nuestro entorno físico, los seres humanos cada vez encontramos menos retos a nuestro alrededor, sin tener que adaptarnos a las fuerzas naturales que nos rodean. Cuán fácil resulta conducir un automóvil moderno, repleto de microcomputadoras que nos ayudan a manejar, en comparación con un vehículo más antiguo equipado con transmisión manual y carente de complicados instrumentos computarizados. Sin embargo, el viejo coche propiciaba las habilidades físicas y mentales de su conductor, las cuales ya no son necesarias en esta era de la "excarnación".

${ }^{24}$ Este análisis se da en el cap. 4 de la Philosophy of Money, esp. sec. III: Georg Simmel, Philosophie des Geldes, 3a. ed., 1920, Munich y Leipzig, Duncker \& Humblot. 
No resulta nada fácil obtener conclusiones a partir de estas reflexiones. Queda claro que la era digital presenta riesgos considerables para el desarrollo de la subjetividad humana. No obstante, condenarla por culpa de estos riesgos sería prematuro y fútil: fútil porque, salvo que ocurra un desastre de gran magnitud, el progreso humano parece ser imparable; prematuro porque, como ya lo he indicado, todavía carecemos de la perspectiva y del conocimiento que son necesarios para una evaluación completa de las implicaciones de la revolución digital. Así pues, por poner un ejemplo, ni siquiera he mencionado el hecho de que las computadoras y otros artefactos afines suelen ser utilizados ampliamente para practicar juegos muy populares. El objetivo de esos juegos es presentar una experiencia de ninguna manera fácil, que desafíe al jugador y le ayude a cultivar sus capacidades mentales e incluso motrices. ¿Podría ser esta un área en la que el mundo digital abre oportunidades para un auténtico desarrollo del ser?

También hemos averiguado que, si bien el texto digital constituye de diversas maneras un desarrollo radical de la página impresa (por ejemplo, al facilitar la búsqueda y manipulación de textos), también puede comportarse como sus predecesores, los manuscritos premodernos. Así pues, por ejemplo, los textos electrónicos no poseen las cualidades estáticas que son características de los impresos, por lo que favorecen la interacción entre el texto y el lector o, mejor dicho, los lectores. Esto es, a pesar de que la pantalla es tan privada como un libro impreso y puede ser transportada con la misma facilidad, al mismo tiempo que está conectada a una red. De esta manera, los lectores pueden comunicarse lo que están leyendo, anotando, comentando y modificando el texto con suma facilidad. Internet tiene potencial para construir nuevos modos de formar comunidad alrededor de un texto.

En consecuencia, espero que por lo menos este ensayo haya servido para llamar la atención sobre las complejidades de su tema y sobre el interés de seguirlo discutiendo filosóficamente. 